\title{
Juristische Beratung
}

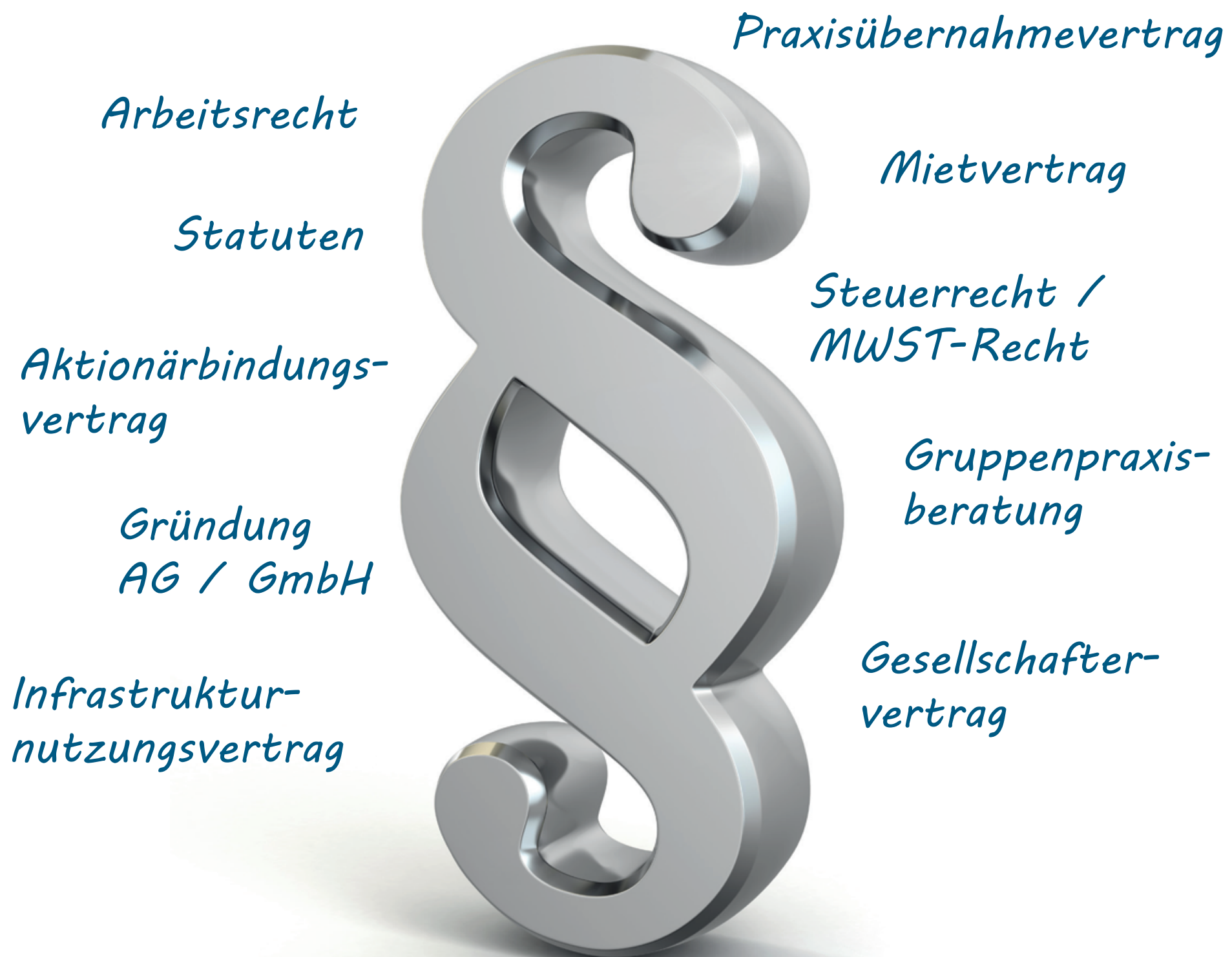

Als Dienstleistungsorganisation der in der Schweiz tätigen Ärztinnen und Ärzte bieten wir Ihnen

- Vertragsausarbeitung und Vertragsprüfung durch Juristen zusammen mit Ökonomen

- Beantwortung Ihrer Fragen zum Arbeitsrecht und Steuerrecht (inkl. MWST-Recht)

- Ausarbeitung von Statuten für juristische Personen sowie Personal- und Führungsreglemente

\section{JURISTISCHE BERATUNG}

\section{Ț FMHSERVICES}

Kontaktieren Sie uns unverbindlich per Telefon bzw. Mail, oder senden Sie uns diesen Antworttalon per Fax oder Post, und wir kontaktieren Sie.

Vorname / Name

Adresse

PLZ / Ort

Telefon Privat / Geschäft

Beste Zeit für einen Anruf

E-Mail-Adresse

\section{CONSULTING}

FMH Consulting Services AG

Burghöhe 1, 6208 Oberkirch

Tel. 0419250077 - Fax 0419250067

mail@fmhconsulting.ch - www.fmhservices.ch 